\title{
Library and Information Sciences Research Literature in Sri Lanka: A Bibliometric Study
}

\section{Author}

\section{Gunasekera, Chamani}

MLIS (Colombo), ASLLA

Senior Assistant Librarian

University of Peradeniya

Peradeniya, Sri Lanka

\section{Contact Details}

Tele:

00-94-81-2392482

Email: chamanig@yahoo.com

\section{Abstract}

This paper presents a bibliometric study of LIS research literature emanating from Sri Lanka over 141 articles from the two LIS journals for the period from 1997 to 2007.Data collected from the two journals namely Journal of University Librarian's Association (JULA) and the Sri Lanka Library Review were analyzed to examine the type of LIS research, areas of LIS research and research strategies and data collection methods used by the LIS researchers in Sri Lanka. This paper also 
attempts to present an analysis of the authorship pattern, author productivity and prominent contributors, citation pattern, length of papers, language wise and year wise distribution of articles growth and direction of LIS research papers over a period of ten years. The study is quantitative oriented and longitudinal in character. Sri Lanka LIS research output seems to concentrate in the area of "LIS Activities" and "Information Seeking" . Some of other important findings are most articles (94\%) are single authored, author productivity is not in agreement with the Lotka's Law. There is no definite growth pattern or positive growth in the area of LIS research in the country. English is the most widely used language. Average citation per article was 9 while average length of an articles was 12 .

\section{Key Words: Bibliometrics, Library and Information science, LIS} Literature, LIS Research and Development

\section{Introduction}

Bibliometrics is associated with the quantitative measurement of documentary materials .It provides measurement that are useful for studying scholarly communication. Traditionally bibliometric studies are used to measure the usage of materials and services within a library or to analyze the historical development of a specific body of literature.

\section{History of Bibliometric studies}

The history of bibliometrics go back more than a century yea.. The statistical analysis of scientific literature began more than 50 years before 
the term "bibliometrics" even was coined in 1969. The emerging field was described in terms such as "Statistical Bibliography". (Parnell,2008)

The word "Bibliometrics" has been derived from Greek words, Biblio means Book and Metrikos meaning Measurement, referring to the science of measurement relating to

Books.(Dhiman,2000)

Allan Pritchard first introduced the term bibliometric in 1969 to denote the "the application of mathematical methods to books and other media of communication". According to him definition and purpose of bibliometric is to shed light on the process of written communication and of the nature and course of a discipline (in so far as this is displayed through written communication) by means of counting and analyzing various facets of written communication. Quantitative analysis can measure the growth, scattering of articles in different journals or to measure the obsolescence of literature in different discipline. (Prtitchard ,1969)

According to British standards Institution, it is the study of the use of documents and pattern of publication in which mathematical and statistical methods have been applied (British standards institution, 1976)

More recently Sengupta had defined this term as the "organization, classification and quantitative evaluation of publication pattern of all macro and micro communications along their authorships by mathematical and statistical calculus. (Senguptha,1990) 
Fairthome defines bibliometrics as the "Quantitative treatment of properties of recorded discourse and behavior appertaining to it"( Fairthome,1969) According to Potter, it is the study and measurement of the publication pattern of all forms of written communication and their authorship" (Potter,1981) Many definitions covering various aspects of bibliometrics are available, but the common feature noted in all these definitions is the emphasis on quantitative aspect.

Bibliometric is a major sub-discipline of quantitative research. This tool traditionally used by the library and information science professionals for studying the communication process, information flows, and the others for better understanding and effective management and dissemination of information. (Rajendran, 2007) It has extensive application in the field of LIS particularly with regard to studying the trends in a subject. It helps in formulating need based development policy and provides objective data to inform managers to take timely decisions. (Jena , 2006) The European information science journals, bibliometrics investigations began to popular in the 1970s and 1980s. Hungary, eastern Germany and Switzerland were the countries which started to do research in bibliometrics since the beginning of the research era

Although famous Bradford's law (1934) of scattering ,Lotka's Law (1926) of scientific productivity are regarded as milestones in bibliometrics, but bibliometric research actually started in late sixties. Later in the seventies and eighties, bibliometrics research took a distinct shape and emerged as a prominent discipline. With the advent of information and communication technology (ICT), web technology and availability of different databases online, the field of bibliometrics gain a momentum. 


\section{Bibliometric studies on LIS research Literature}

The literature of library and information science as a discipline has been extensively researched from a variety of perspectives. The systematic study of subject trends in L IS literature has been justified as a self reflexive exercise to determine the historical roots of present library practice (Atkins, 1988) and to predict research trends in future. Wersing and Neveling (1976) presented one early reflexive analysis of LIS .Their normative view of LIS has been contrasted with empirical analysis where subject classifications, and methodological approaches were derived from an examination of literature samples.(Cano,1999) Various contact analyses of LIS research publications have been made by many scholars around the world. These content analysis of LIS research publications can be roughly divided into two types in several ways: One method distinguishes between analyses, analyzed samples published in the short term (generally in one year) and in the long term: these analyses can also be divided at the national and international levels: or, in the comprehensive fields of LIS and in the limited fields of LIS. Although these studies have some kind of deficiencies, they all have contributed to the development of this research subject.(Cheng,1996)

For this study mainly used as a base of the research articles of two well known scholars in this felid Jarvelin and Vakkari in 1990.In general, the content analysis model of Jarvelin and Vakkari consists of three parts:

1. The distribution of the articles over the topic

2. The approaches: viewpoints on information dissemination and social levels; and, 
3. The methods: research strategies and data collection methods (Cheng,1996)

It is difficult to identify the categories of the authors of LIS articles in Sri Lanka. Therefore only two parts of Jarvelin's and vakkari model use for data analyzing in this study.

1. The distribution of the articles over the topic

2. The methods: research strategies and data collection methods

At present, it is difficult to derive an adequate understanding of the development of particular LIS subject areas, their theoretical foundations, and preferred methodological approaches because results reported in the literature are not comparable.(Jarvelin and Vakkari, 1990)

Though bibliometrics has quite long history in the world very few studies on bibliometrics in LIS research literature found in Sri Lanka.

\section{Objectives of the study}

The aim of this study is to study the growth and related aspects of LIS research literature for the period from 1997 to 2007 in Sri Lanka .The objectives of the study are:

1. to examine the characteristics of LIS research, research strategy used and data

collection method

2. to assess the growth of literature 
3. to study the Authorship pattern, authorship productivity ,

4. to study citation pattern and self citations

5. to find length of papers

6. to find most productive authors

7. to study author's affiliation

\section{Methodology and data collection}

Criteria for journal selection

In order to examine the characteristics and trend of the LIS research in Sri Lanka two reputed journals have been selected and the criteria for selection these two journals was regularization of publication which was necessary for longitudinal data analysis.

This study focused the articles published in the Journal of University librarian's Association (JULA) publish by the University librarian's Association in Sri Lanka and the Sri Lanka Library Review publish by Sri Lanka Library Association. The database of the study comprised 141 articles published in these two journals from 1997 to 2007. In the study each individual article was scanned, checked, examined and tabulated for necessary data in to separate sheets in terms of subject of article, research strategy and date collection method used ,names of authors, number of authorship, author's institutional affiliation, number of references, author's self citation, length of article, year of article etc.

\section{Classification Scheme}

The classification scheme for topics of LIS by Jarvelin and Vakkari (1990) was constructed of LIS and it's subfield (Appendix 1) was adapted in 
order to examine the nature of LIS research in the country. The data were collected and classified using the classification scheme devised by them. The main classes of LIS topics as follows:

\section{The Profession}

\section{Library History}

3.Publishing and book history

4.Education in LIS

5. methodology /Analysis of LS

6. Library and information service activities

7. Information storage and retrieval

8. Information seeking

9. Scientific and professional communication

10.Other LIS topic (other aspect of LIS)

11. Other Study ( other disciplines

Since the focus of this paper is not analyzing the contents of the articles, the author used only the classification headings mentioned above. The classification scheme divides LIS topics into 11 major classes with their respective subclasses.(Appendix I) Each article was classified under only one main subclass. When an article dealt with more than one topic, only its main topic is considered.

In addition to the classification scheme, Jarvelin and Vakkari also presented a classification of research strategies.

M 10. Empirical research strategy

M 20. Conceptual research strategy

M 30. Mathematical /logical method

M 40. System/software analysis design 
M 50 Literature Review

M 60 Discussion paper

M 70 Bibliographic method

M 80 Other method

M 90 No method/Not applicable

Each methodological category was subdivided into more specific method, for example, the empirical research strategy subdivide into 11 more specific methodologies such as Historical method ,Survey method, Qualitative method, Evaluation method etc.(Appendix II)

The classification of research methods scheme is further developed as the scheme of data collection methods. In this scheme Jarvelin and Vakkari identified 10 data collection methods such as:

C1. Questionnaire, interview

C2. Observation

C3. Thinking Aloud

C4. Content analysis

C5. Citation analysis

C6. Historical source analysis

C7. Several method of collecting

C8. Use of data collected earlier

C9. Other method of collecting

C10. Not applicable

Each article published in the two LIS journals chosen was read and classified according to theme, methodology employed and data collection method used and noted down according to the year of publication. 


\title{
Authorship as productivity variable
}

The following variables were identified per articles.

\author{
1. Name of author \\ 2. Number of author per article \\ 3. Author's affiliation \\ 4. Author's self-citations \\ 5. Most productive authors in the field
}

\section{Other variables}

In order to presenting comprehensive overview of LIS research literature following variables were also identified per article and noted down according to the year.

1. Literature growth (Year wise distribution of paper)

2. Citation pattern (No of citations per article and self citations of author)

3. Length of article (Pages of article)

4. Language of article

\section{Results and discussion}

\section{Growth of LIS literature}

Table 1 depicts the growth of research literature of LIS. 
Table 1: Year wise distribution of papers

\begin{tabular}{|l|l|l|l|}
\hline Year & No. of articles & $\begin{array}{l}\text { Cumulative of } \\
\text { articles }\end{array}$ & of articles \\
\hline 1997 & 9 & 9 & 6 \\
\hline 1998 & 20 & 29 & 14 \\
\hline 1999 & 10 & 39 & 7 \\
\hline 2000 & 15 & 54 & 11 \\
\hline 2001 & 7 & 61 & 5 \\
\hline 2002 & 15 & 76 & 11 \\
\hline 2003 & 15 & 91 & 11 \\
\hline 2004 & 13 & 104 & 9 \\
\hline 2005 & 12 & 116 & 8.5 \\
\hline 2006 & 12 & 128 & 8.5 \\
\hline 2007 & 13 & 141 & 9 \\
\hline
\end{tabular}

Table I does not indicate any definite growth pattern of the literature. During the ten year period the high decline of literature has been observed in year 1997 and 2001. The reason may be only one journal published (Library review) in these years. The highest number of articles (20) was published in year 1998 and there after a gradual decline is seen. However in last four years the growth of literature static with 12/13 articles per year which appear to be insignificant in terms of world LIS research literature.

\section{Language of publication}

It is also important to note the language of publication. As usual English is the predominant language of publication. (Table 2) 
Table 2: Language wise distribution

\begin{tabular}{|l|l|l|l|l|}
\hline Year & $\begin{array}{l}\text { Language } \\
\text { English }\end{array}$ & Sinhalese & Tamil & Total \\
\hline 1997 & 7 & 1 & 1 & 9 \\
\hline 1998 & 16 & 3 & 1 & 20 \\
\hline 1999 & 9 & 1 & & 10 \\
\hline 2000 & 14 & 1 & & 15 \\
\hline 2001 & 6 & 1 & & 7 \\
\hline 2002 & 12 & 2 & 1 & 15 \\
\hline 2003 & 12 & 2 & 1 & 15 \\
\hline 2004 & 11 & 1 & 1 & 13 \\
\hline 2005 & 8 & 3 & 1 & 12 \\
\hline 2006 & 11 & 1 & & 12 \\
\hline 2007 & 11 & 2 & & 13 \\
\hline Total & 117 & 18 & 6 & 141 \\
\hline
\end{tabular}

Table 2 indicates that out of 141 articles, English occupies the first position with 117 articles.(83 \%)

\section{Distribution of research articles over topics}

Table 3 presents the distribution of articles over the topics. 


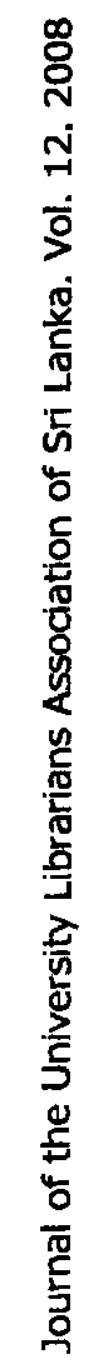

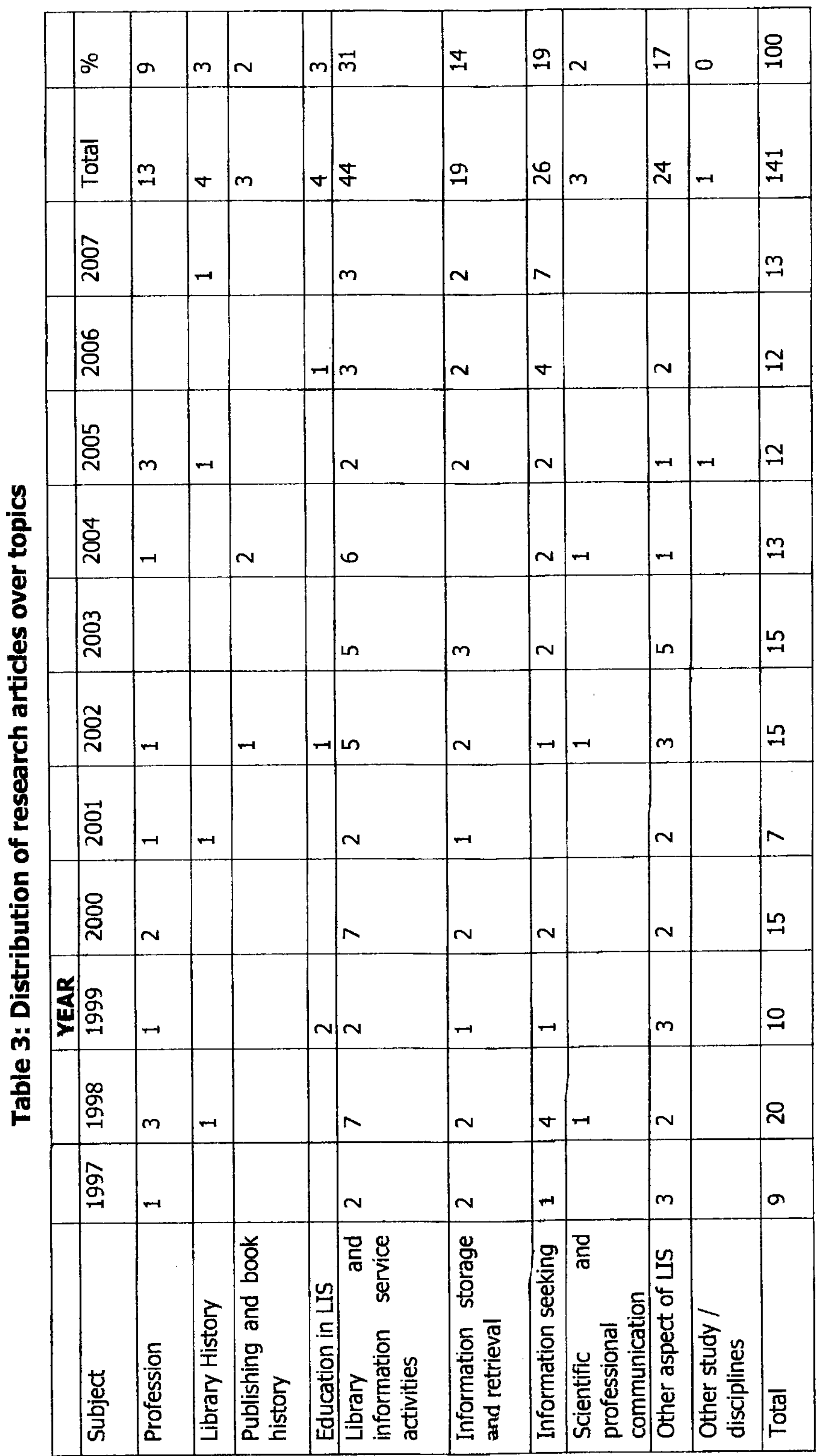


The Table 3 shows that the highest number of articles covered within the period of this study is under the heading of Library and information service activities with 44 articles (31\%). Information seeking is the second most popular topic with 26 articles while other aspect of LIS is in the third with 24 articles. The analysis reveals that the information retrieval is in fourth place with 19 articles.

Further table 3 indicates that there is no definite growth pattern for any topic covered by the articles.

\section{Research strategies used in the articles}

The distribution of the research strategies in the articles from 1997 to 2007 is shown in the table 4. 


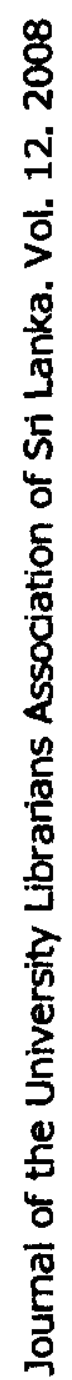
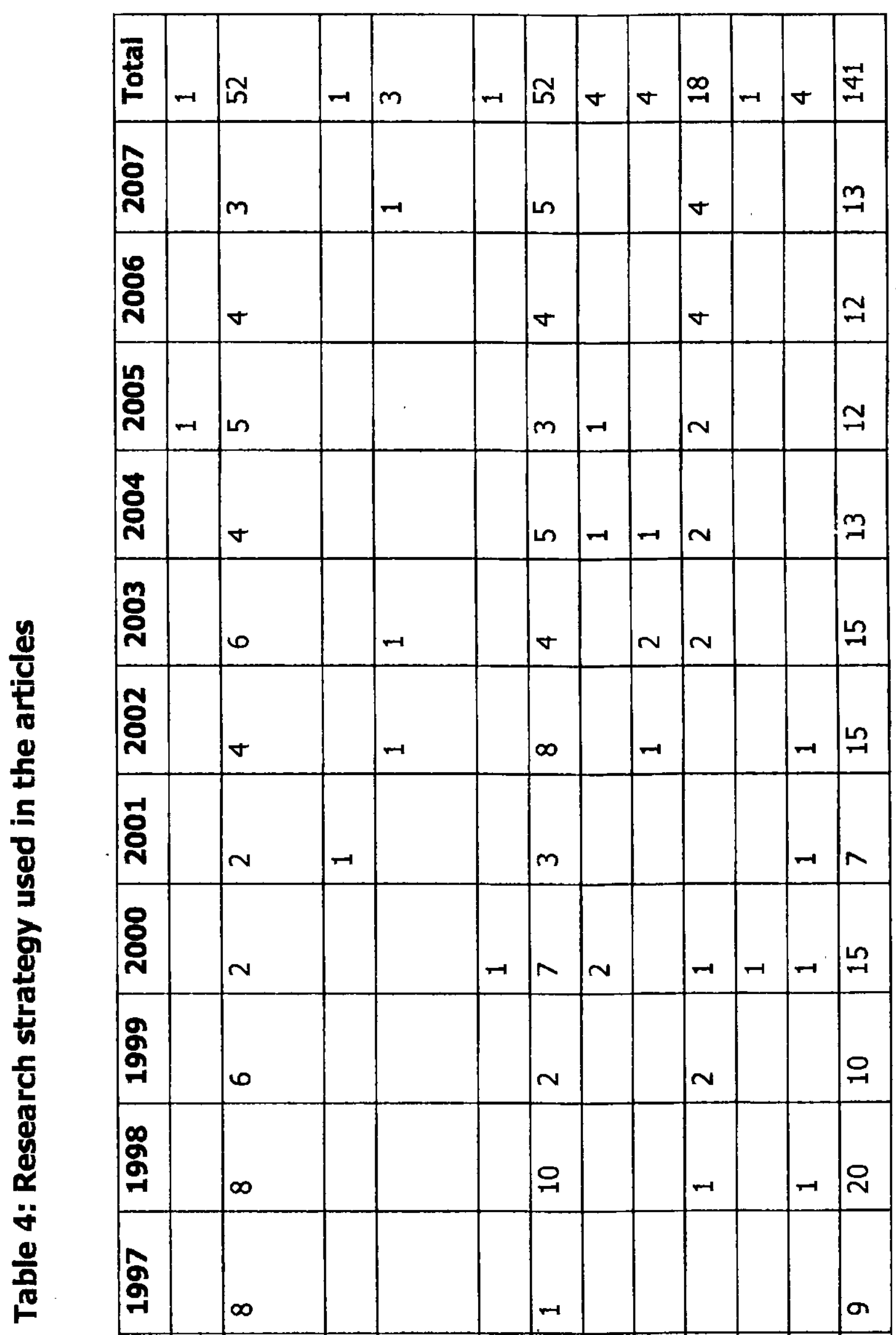

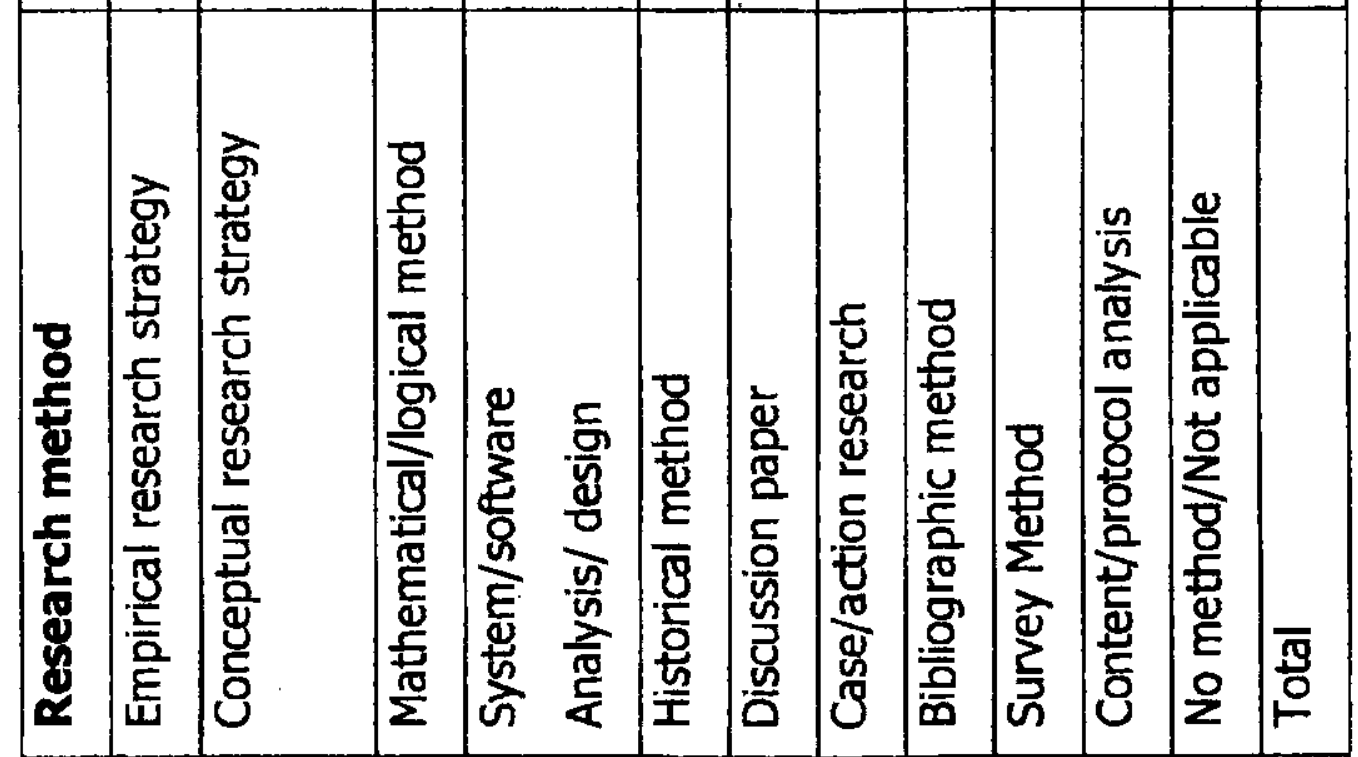


The most popular research strategies used by LIS researchers were conceptual research method and the discussion paper which was in equal number ( 52) of articles. Table 4 further shows that a continuous increase in the use of the survey method from the year 2003. Mathematical/Logical method and content or protocol analysis method are less likely to be used in research literature in Sri Lanka.

\section{Data Collection method used for LIS research}

Data collections methods used for the research strategies are given in table 5 . 


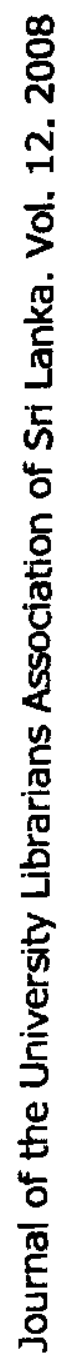

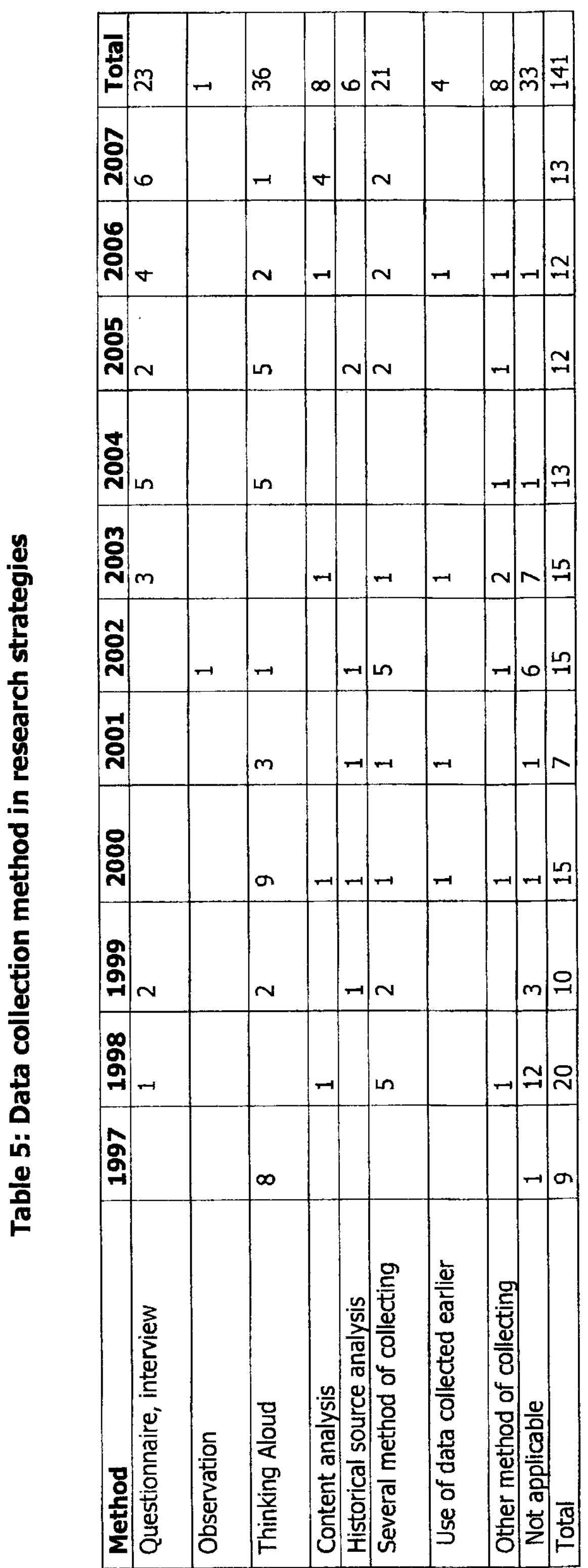


Table 5 shows that the Thinking aloud is the most frequent data collection method was used for LIS research in Sri Lanka. The Questionnaire, interview and the Several method of collecting were also used for the LIS research. Surprisingly, $23 \%$ of studies (33) were not applied any data collection method for the study. (Not applicable)

\section{Authorship pattern and author productivity}

Table 6 shows the authorship pattern of the articles.

Table 6: Authorship pattern

\begin{tabular}{|l|l|l|l|l|l|}
\hline Year & Single & Joint & Three & Four & Total \\
\hline 1997 & 9 & & & & 9 \\
\hline 1998 & 20 & & & & 20 \\
\hline 1999 & 10 & & & & 10 \\
\hline 2000 & 13 & 2 & & & 15 \\
\hline 2001 & 7 & & & & 7 \\
\hline 2002 & 15 & & & & 15 \\
\hline 2003 & 13 & 2 & & & 15 \\
\hline 2004 & 13 & & & & 13 \\
\hline 2005 & 12 & & & & 12 \\
\hline 2006 & 11 & & 1 & & 12 \\
\hline 2007 & 8 & 3 & 1 & 1 & 13 \\
\hline Total & 131 & 7 & 2 & 1 & 141 \\
\hline
\end{tabular}

Table 6 reveals that 131 articles (93\%) out of 141 are of the single authorship. Seven articles (5\%) were written by two authors and 2 articles $(1.3 \%)$ by three authors. Only one article was written by multiple authors ( 4 authors) which is $0.7 \%$ of the total contribution. 


\section{Author Productivity}

Lotka's Law has been used to measure the productivity of authors. It states that " the number of authors making " $r$ " contributions is about $1 / n 2$ of those making one; and the proportion of all contributors, that make a single contribution, is about 60 percent." This means that in a given subject out of all authors, about 60 percent will have just one publication and 15 percent will have two publications, 7 percent of authors will have three publications and so on. According to Lotkas's Law of scientific productivity, only six percent of the authors in a field will produce more than 10 articles. Table 7 presents author productivity.

Table 7: Author Productivity

\begin{tabular}{|l|l|l|l|}
\hline Se. no & No. of articles & No. of authors & Observed (\%) \\
\hline 1 & 1 & 45 & 63 \\
\hline 2 & 2 & 11 & 15 \\
\hline 3 & 3 & 7 & 10 \\
\hline 4 & 4 & 3 & 4 \\
\hline 5 & 5 & 2 & 3 \\
\hline 6 & 6 & 2 & 3 \\
\hline 7 & 9 & 1 & 1 \\
\hline 8 & 10 & 1 & 1 \\
\hline
\end{tabular}

A total of 72 authors contributed 141 articles over the period of study. Of these authors, 45 contributed one article each, 11 contributed two articles each , 7 contributed 3 articles each and 3 contributed four articles each. Two sets of two different authors contributed 5 and 6 articles each. Lastly two sets of different authors contributed 9 and 10 articles each. 
Table 7 reveals that the percentage of authors contributed only one article each was $63 \%$ (45) which is larger than the original $60 \%$ Lotka's data. On average 1.98 (Approx.2) articles published by each author. The Largest number of articles were contributed by an author is 10 . As can be seen $15 \%$ of authors contributed to two articles which exactly match with the Lotka's Law. But in general the results do not match with Lotka's Law.

\section{Ranking of most productive author}

Table 8 presents the most productive authors in the LIS research area.

Table 8: Rank list of productive authors in the field

\begin{tabular}{|l|l|l|}
\hline Name of Author & No.of contributions & Rank \\
\hline N.U.Yapa & 10 & 1 \\
\hline Sriyani Illeperuma & 9 & 2 \\
\hline W.R.G.Silva & 6 & 3 \\
\hline M.B.M.Farooz & 6 & 3 \\
\hline Ruwan Gamage & 5 & 4 \\
\hline Pradeepa Wijetunga & 5 & 4 \\
\hline Sumana Jayasuriya & 4 & 5 \\
\hline Sriyani Perara & 4 & 5 \\
\hline Geetha Yapa & 4 & 5 \\
\hline 7 authors & 3 & 6 \\
\hline 11 authors & 2 & 7 \\
\hline 45 authors & 1 & 8 \\
\hline
\end{tabular}


Table 8 shows that the most productive authors are N.U.Yapa who contributed 10 articles and Sriyani Illeperuma with 9 articles. Followed by W.R.G.Silva and M.B.M.Farooz both with six articles each. Padeepa Wijetunga and Ruwan Gamage are ranked fourth with 5 articles each. Followed by Sumana Jayasuriya,Sriyani Perera and Geetha Yapa with 4 articles each. Seven authors who contributed 3 articles each have taken the sixth place of ranking. Eleven authors with 2 articles and lastly 45 authors with 1 article each. It is noted that the most of the top six rank authors were affiliated with higher education institutions.

\section{Author's Institutional affiliation}

Institutional affiliation of authors is divided into three categories namely higher educational institutions, government institutions and private organizations.

Table 9 presents the distribution of authors by institutional affiliation.

\section{Table 9: Institutional Affiliation}

\begin{tabular}{|l|l|l|}
\hline Sequence .no & Institution & No. of contribution \\
\hline 01 & $\begin{array}{l}\text { Higher Education institutions } \\
\text { (Universities) }\end{array}$ & 93 \\
\hline 02 & $\begin{array}{l}\text { Government institutions } \\
\text { Private organizations }\end{array}$ & 33 \\
\hline 03 & $\begin{array}{l}\text { Not mentioned } \\
\text { (Not affiliated) }\end{array}$ & 9 \\
\hline & Total & 141 \\
\hline
\end{tabular}


Above table reveals that out of 141 articles, the majority are written by authors affiliated to the universities with a total of $93(66 \%)$ articles. Followed by government organizations 33 articles (24\%) and only 6 articles (4\%) by the private organizations. Institutional affiliation of 9 authors (6\%) could not be ascertained.

\section{Citation pattern}

The distribution of citation pattern is given in table 10 .

Table 10: Citation pattem

\begin{tabular}{|l|l|l|l|l|l|l|}
\hline Year & $\begin{array}{l}\text { No. of } \\
\text { articles }\end{array}$ & $\begin{array}{l}\text { Cumulative } \\
\text { total } \\
\text { of articles }\end{array}$ & $\begin{array}{l}\text { No. of } \\
\text { citations }\end{array}$ & $\begin{array}{l}\text { Cumulativ } \\
\text { e total of } \\
\text { citations }\end{array}$ & $\begin{array}{l}\text { Average } \\
\text { citation } \\
\text { per } \\
\text { article }\end{array}$ & $\begin{array}{l}\text { Cumulat } \\
\text { ive } \\
\text { average } \\
\text { of } \\
\text { citation } \\
\text { s }\end{array}$ \\
\hline 1997 & 9 & 9 & 25 & 25 & 2.78 & 2.78 \\
\hline 1998 & 20 & 29 & 207 & 232 & 10.35 & 8 \\
\hline 1999 & 10 & 39 & 134 & 366 & 13.4 & 9.38 \\
\hline 2000 & 15 & 54 & 77 & 443 & 5.13 & 8.2 \\
\hline 2001 & 7 & 61 & 33 & 476 & 4.71 & 7.8 \\
\hline 2002 & 15 & 76 & 99 & 575 & 6.6 & 7.57 \\
\hline 2003 & 15 & 91 & 156 & 731 & 10.4 & 8.03 \\
\hline 2004 & 13 & 104 & 114 & 845 & 8.78 & 8.13 \\
\hline 2005 & 12 & 116 & 139 & 984 & 11.58 & 8.48 \\
\hline 2006 & 12 & 128 & 116 & 1100 & 9.67 & 8.59 \\
\hline 2007 & 13 & 141 & 129 & 1229 & 9.92 & 8.72 \\
\hline
\end{tabular}


The table 10 presents the year wise distribution of citations in the articles and the average of citations thereof, total number of citations and average citations per article. Table 10 reveals that total of 1229 citations distributed among 141 articles. It is also seen that the number of articles are increasing but not in a uniform manner. Similarly, the number of citations per year is varying from year to year. The highest number of citations per article is in the year 1999 and the lowest number of citations per article is in the year 1997.

\section{Author self- citation}

The frequency of author self citations in the references of the articles are identified in table 11.

Table 11: Author self citation

\begin{tabular}{|l|l|l|}
\hline Self citation & Frequency & Percentage \\
\hline Yes & 11 & 8 \\
\hline No & 130 & 92 \\
\hline Total & 141 & 100 \\
\hline
\end{tabular}

Out of 141 of total articles only $11(8 \%)$ contained author's self citations. This indicated that some of the contributors of the two journals under study are quite productive and are continuously working towards contributing more articles to LIS journals.

\section{Length of articles}

Table 12 contains distribution of articles according to their length. 
Table 12: Distribution of papers according to length

\begin{tabular}{|l|l|l|l|l|l|l|}
\hline Year & $\begin{array}{l}\text { No. of } \\
\text { articles }\end{array}$ & $\begin{array}{l}\text { Cumulative } \\
\text { total of } \\
\text { articles }\end{array}$ & $\begin{array}{l}\text { No. } \\
\text { of } \\
\text { pages }\end{array}$ & $\begin{array}{l}\text { Cumulative } \\
\text { total of } \\
\text { pages }\end{array}$ & $\begin{array}{l}\text { Average } \\
\text { pages } \\
\text { per } \\
\text { articles }\end{array}$ & $\begin{array}{l}\text { Cumulative } \\
\text { average } \\
\text { no. of } \\
\text { pages }\end{array}$ \\
\hline 1997 & 9 & 9 & 61 & 61 & 6.78 & 6.78 \\
\hline 1998 & 20 & 29 & 226 & 287 & 11.3 & 9.9 \\
\hline 1999 & 10 & 39 & 114 & 401 & 11.4 & 10.28 \\
\hline 2000 & 15 & 54 & 181 & 582 & 12.07 & 10.78 \\
\hline 2001 & 7 & 61 & 76 & 658 & 10.86 & 10.79 \\
\hline 2002 & 15 & 76 & 221 & 879 & 14.73 & 11.57 \\
\hline 2003 & 13 & 91 & 177 & 1056 & 13.62 & 11.6 \\
\hline 2004 & 13 & 104 & 149 & 1205 & 11.46 & 11.59 \\
\hline 2005 & 12 & 116 & 150 & 1355 & 12.5 & 11.68 \\
\hline 2006 & 12 & 128 & 168 & 1523 & 14 & 11.9 \\
\hline 2007 & 13 & 141 & 209 & 1732 & 16.08 & 12.28 \\
\hline
\end{tabular}

Table 12 reveals that the average length of articles is 12.28 pages. Further it has been observed that the average length of articles varied from a minimum of 6.78 pages to a maximum of 16.08 pages.

\section{Conclusion}

The following conclusions are drawn from the study.

1. It is seen that there is no definite growth pattern or positive growth of LIS research articles published from 1997 to 2007. 
2. The subject wise analysis of the contents of the articles revealed that Library and Information services activities (LIS) was prominently studied (31\%) in the LIS field.. LIS research literature in Sri Lanka seems to concentrate mostly in the area of LIS activities, Information seeking, other aspects of LIS and Information storage \& retrieval. In combination they covered over $81 \%$ of research articles. In general the findings of the study indicate that the LIS research in the country has not changed greatly during the ten years period.

3. The research strategies most frequently used by LIS researchers were conceptual research and the discussion papers whereas the least frequent were empirical, mathematical and historical methods. These results indicate that the selection of research strategies by LIS researchers in Sri Lanka is more towards the survey types.

4. The most frequent data collection method used for the LIS research in Sri Lanka was "Thinking Aloud".

5. Single authorship is prominent in the LIS field.

6. It was found that the author productivity is not match with the Lotka's Law. The most prolific author is in the field was N.U.Yapa who contributed 10 articles. Majority of top ranked authors are affiliated to the Universities.

7. The average citations per article are $9(8.72)$. 
8. The articles have an average of 12 (12.28) pages which shows the reasonable length of a research article.

\section{References}

Atkins,S.E.(1998) Subject Trends in Library and Information Science Research 1975-1984.Library Trends, 36 P 633-658

British Standards Institution (1976) British standards Glossary of Documentation Terms. Prepared under the Directives of the Documentation Standard Committee p.7

Cano,V.(1999) Bibliometric Overview of Library and Information Science research in Spain. Journal of the American society for Information science , 50(8) 675-680

Dhiman,A.K.(2000) Ethno botany journal: A ten year Bibliometric study. Iaslic Bulletin, 45(4) 177-182

Fairthome, R.A. (1969), Empirical by parabolic distribution (Bradford, ZipF-Maud/bart) for bibliometric description and prediction. Journal of Documentation, 125(1) 319

Huanwen, Cheng (1996) A bibliometric study of Library and Information research in China: proceedings of the $62^{\text {nd }}$ IFLA General conference held at the Beijing, China

Jarvelin, K and Vakkari, P.(1990) Content analysis or research articles in library and information science. Library and Information science, $12 \mathrm{p}$ $395-421$ 
Jena, Kamal Lochan (2006) A bibliometric analysis of the Journal "Indian Journal of Fibre and Textile research. Annals of Library and Information studies, 53(1) 22-30

Patra, Swapan Kumar et al.(2006) Bibliometric study of Literature on Bibliometrics. DESIDOC Bulletin of Information Technology, 26(1) 27-32

Parnell, Staffan (2008) Bibliometrics ; Background. Swedish University of Agriculture Sciences Libraries .Available from: http://www.bib.slu.se/bibliometri/ebakgrund.html (Accessed on 10.06.2008)

Potter, W.G. (1981) Lotka's Law Revisited. Library Trends, 30(1) 31-35

Pritchard,A.(1969) Statistical Bibliography or Bibliometrics? Journal of Documentation, 25(4) 348-349

Rajendran, P. and Parihar, Y.S. (2007) A bibliometric study of Laser literature in India 1995-2005. Annals of Library and Information Studies, $54(2) 112-118$

Sengupta, I.N. (1990) Bibliometrics and its application. New Delhi , Atlantic Publishers 165-191

Wersig, G. and Neveling. U.(1976)The Phenomenon of interest to information science. The Information scientist, 9 p 127-140 


\section{APPENDIX 1}

\section{THE CLASSIFICATION SCHEME}

- Professions

- Library history

- Publishing and book history

- Education in LIS

- Methodology/Analysis of LIS

- Library and Information service activities

Circulation or interlibrary loans

- Collections

- Inf. or ref. service

- User education

- Buildings or facilities

- Administration of planning

- Automation (except when concerned with some particular activity)

- Other L\&I service activities

- Other L\&I service activities

- Several interconnected L\&I activities

- Information storage and Retrieval

Cataloguing

- Classification and indexing (process or languages)

- Information retrieval

- Bibliographic databases or bibliographies

- Nonbibliographic data bases (textual, numeric...) 
- information seeking

Information dissemination

- The use/users of information channels/sources

- The use of L\&I services (no other channels considered)

- Information seeking behavior (focus on persons)

- Information use (whether (and how) used)

- Information management

- Scientific and professional communication

Scientific or professional publishing

- Citation patterns and structures

- Other aspects of communication

- Other LIS Topic

- Other study (other discipline)

\section{APPENDIX II}

\section{METHODS - RESEARCH STRATEGY}

Empirical research strategy

- Historical method

- Survey method

- Qualitative method

- Evaluation method

- Case or action research method

- Content or protocol analysis

- Citation analysis

- Other bibliometric method

- Secondary analysis 
- Experiment

- Other empirical method

Conceptual research strategy

- Verbal argumentation, criticism

- Concept analysis

- Mathematical or logical method

- System/software analysis/design

- Literature review

- Discussion paper

- Bibliographic method

- Other method

- Not applicable, no method 